\title{
Navigating and negotiating: Career changers in Teacher Education
}

\author{
programs
}

\section{First/Contact Author:}

\begin{tabular}{|l|l|}
\hline Name & Meera Varadharajan \\
\hline Title & $\mathrm{Dr}$ \\
\hline Institution & University of Technology Sydney \\
\hline Phone & 0431532074 \\
\hline Email & Meera.Varadharajan@uts.edu.au \\
\hline Postal address & PO Box 123, Broadway, NSW 2007, Australia \\
\hline $\begin{array}{l}\text { Ethics statement } \\
\text { included in body of } \\
\text { manuscript (if relevant) }\end{array}$ & $\begin{array}{l}\text { Ethics approval was granted by the relevant university for this } \\
\text { study Informed consent was given by all participants through } \\
\text { their choice to anonymously respond to the survey. }\end{array}$ \\
\hline Four (4) key words & $\begin{array}{l}\text { Career change student teachers; mature age learners; teacher } \\
\text { education programs; negotiating change }\end{array}$ \\
\hline
\end{tabular}

\section{Secondary Authors:}

\begin{tabular}{|l|l|}
\hline Name & John Buchanan \\
\hline Title & Associate Professor \\
\hline Institution & University of Technology Sydney \\
\hline
\end{tabular}




\begin{tabular}{|l|l|}
\hline Title & Professor \\
\hline Institution & University of Technology Sydney \\
\hline
\end{tabular}

\section{Author Biographies (approx. 25 words each)}

\begin{tabular}{|l|l|}
\hline Meera Varadharajan & $\begin{array}{l}\text { Meera Varadharajan's research and teaching interests are in } \\
\text { teacher education, sociology of education; beginning } \\
\text { teachers, career change teachers, global education, } \\
\text { educational philosophy and teacher quality. }\end{array}$ \\
\hline John Buchanan & $\begin{array}{l}\text { John Buchanan's research and teaching } \\
\text { interests include teacher quality and retention, beginning } \\
\text { teachers, sociology and social justice, and intercultural } \\
\text { education, including transitions. }\end{array}$ \\
\hline Sandy Schuck & $\begin{array}{l}\text { Sandy Schuck's research interests include induction and } \\
\text { mentoring of early career teachers, teacher professional } \\
\text { learning, teacher education futures, mobile learning and } \\
\text { technology-enhanced learning. }\end{array}$ \\
\hline
\end{tabular}

\section{Acknowledgements (Optional)}

The authors would like to thank the Australian Teacher Education Association (ATEA) who funded the project on career change student teachers. We would also like to thank the preservice teachers for their valuable participation in the survey. 


\title{
Navigating and negotiating: Career changers in Teacher Education programs
}

\begin{abstract}
Career changers form a substantial proportion of teacher education (TE) students. They bring a broader set of life and work experiences than do their younger, school-leaving counterparts. This paper investigates the needs and concerns of career change student teachers (CCSTs) in Australia. The study on which this article reports analysed survey data from 508 CCSTs enrolled in 29 of Australia's 34 universities. The article explores what this group brings to their TE courses, and how their needs and contributions may differ from those of younger students. The data confirmed career changers' reasons for choosing teaching are primarily driven by intrinsic and altruistic motivations. Concerns regarding flexibility in course offerings was expressed. We advise that attracting and retaining career change teachers is likely to become increasingly important in the context of rising school student numbers, teacher attrition, and the impending departure from the profession of many 'baby boomers'.
\end{abstract}

\section{Keywords}

Career change student teachers, mature age learners, teacher education programs, career changers, negotiating change.

\section{Statement of ethics approval}


Ethics approval was granted by the relevant university for this study. Informed consent was given by all participants through their choice to anonymously respond to the survey.

\section{Introduction}

Given the likelihood of wide-scale retirement over the next decade of baby boomer teachers, and the high attrition rate of early career teachers (Weldon, 2018), it is essential to evaluate how teacher education (TE) programs can attract and support newcomers. This article focuses on a significant cohort of student teachers, career-changers, to understand their contributions and concerns. The paper seeks to investigate what this group of students may bring to their TE courses, how their needs and contributions may differ from those of other, younger students, and how they navigate change as students. To date, limited research exists on this group even though the latest Staff in Australia's Schools Survey (SiAS) indicates the proportion of mature age students enrolling in TE programs is increasing (McKenzie, Weldon, Rowley, Murphy \& McMillan, 2014).

Various terms apply to students entering TE programs with prior careers or entering as mature age students. They are sometimes referred to in the literature as non-traditional pre-service teachers (Crosswell \& Beutel, 2017); career-change student entrants (Priyadharshini \& Robinson-Pant, 2003; Varadharajan, 2014); or mature learners (Hamilton \& O’Dwyer, 2018). Here we have adopted the term career-change student teachers (CCSTs).

For the purposes of this study, a CCST is defined as having been employed in a career other than teaching for at least two years, and/or is a mature age student over the age of 25 years, and/or entered the TE program eight years or more after finishing school. 508 CCSTs who belonged to one or more of the above groups across 29 Australian universities responded to an online survey garnering qualitative and quantitative data. This article presents a critical discussion of the findings emerging from this survey. We conclude by proffering recommendations for TE providers, systems and schools.

\section{Review of related literature}


Across all higher education (HE), studies point to challenges faced by mature students, including barriers to entry and completion (Burton, Golding Lloyd, \& Griffiths, 2011; Hoare \& Johnson, 2011). Challenges for adult learners relate mainly to personal and family circumstances, study experiences, geography, and situational and institutional barriers (Burton et al., 2011) making them a "vulnerable cohort" (Hamilton \& O'Dwyer, 2018). Mallman and Lee note that mature age students with little recent involvement in formal learning structures may be anxious about 'fitting into' the university culture, and universities may not be sufficiently receptive, viewing the students as a "liability because they may need different or additional assistance" (2016, p. 686) from their (arguably misidentified) 'mainstream' school-leaver counterparts. Mallman and Lee contend that students are expected to conform to the institution, thus "neutralising the institution's responsibility" (p. 686). Burton et al.'s 2011 study recommended support and advice specifically tailored for individual students. Such tailored communication can be beneficial in eliminating or minimising some of the recognised barriers, such as institution accessibility, financial constraints and family commitments.

While these challenges and supports pertain to all HE students, this article focuses on mature age TE students, given the important role they are likely play in the teacher workforce on graduation. The SiAS survey indicated that one in three early career teachers is likely to be a career-changer. As well, more than one in three student teachers is over 30 years old and $16 \%$ are over 40 years old (McKenzie et al., 2014). CCSTs comprise a diverse group from various backgrounds, possessing a range of characteristics, experiences, learning needs and expectations. While the term career-change suggests career experience prior to joining a TE program, not all mature age entrants have been salary earners. Career changers also refers to those who were self-employed or owned a business (Laming \& Horne, 2013); late-starters (Priyadharshini \& Robinson-Pant, 2003) or those re-commencing studies after a gap, for instance after discharging carer/parental duties (Tigchelaar,Vermunt, \& Brouwer, 2014). For some, the change to teaching could be a second career, but for others, it may be the third or fourth career move. 
The array of prior experience among CCSTs is broad, ranging from the armed forces to tradespeople, to consultants (e.g., Hunter-Johnson, 2015; Laming and Horne, 2013). Career changers' prior educational backgrounds are also diverse, including arts, pure science and management (Tigchelaar et al., 2014). Some career changers enter a TE program with school level qualifications while others have post-graduate qualifications as indicated by the abovementioned studies. They may choose to enter either traditional TE programs or alternative certified pathways, such as the fast-track pathways in the US designed to recruit a diverse group of prospective teachers (Kee, 2012). Depending on their other commitments, CCSTs may express a preference for a distance/online study modes while others may prefer face-to-face lectures (Grier \& Johnston, 2012). Balancing study and other life commitments (such as work and family) can pose additional challenges, and universities need to pay particular attention to supporting the professional and personal learning needs of this cohort if they are to maximise their chances of being successful in their new profession (Hamilton \& O'Dwyer, 2018; Kaldi \& Griffiths, 2013).

CCSTs are likely to be invested in the teaching profession. Studies suggest that careerchangers are often intrinsically driven by a sense of purpose, civic duty and social good (Laming \& Horne, 2013; Richardson \& Watt, 2005; Wilkins, 2017; Williams \& Forgasz, 2009). Personal and professional qualities and attributes of career-changers noted in the literature include passion and commitment (Varadharajan, 2014; Williams \& Forgasz, 2009); in-depth knowledge of subject matter and content knowledge (Watters \& Diezmann, 2015); a deep sense of caring focused on students and their wellbeing (Varadharajan, 2014; Cuddapah \& Stanford, 2015) and effective coping strategies (Crosswell \& Beutel, 2017). However, there are also associated challenges. Career-changers' earlier experiences can influence their teaching and learning conceptions (Tigchelaar, et al., 2014) and they are said to sometimes struggle with their preconceived notions and beliefs about teaching and learning, which can conflict with accepted contemporary practices and approaches (Richardson \& Watt, 2006). Grier and Johnston (2012) question career-changers' ability to transfer and translate prior knowledge and skills to the school context. 
Though some international studies have made recommendations including addressing the needs, expectations and aspirations of career changers (Anthony \& Ord, 2008; Hart Research Associates, 2010; Priyadharshini \& Robinson-Pant, 2003), there is limited Australian literature on CCSTs' diverse characteristics, expectations and learning needs.

The study reported here addresses this gap, contributes to existing literature as well as offering recommendations to HE providers and policymakers to improve our understanding of CCSTs in Australia. Such understandings will enable TE programs, schools and education jurisdictions to better align this cohort with the demands of the teaching profession, thus improving retention. Given the cost of preparing teachers, it is imperative that TE programs support them to become successful and effective. In particular, second career teaching students have personally invested heavily in becoming teachers; it is important that their investment in this new career is realised.

\section{Conceptual framework}

The study adopted a qualitative interpretive framework to extract rich, meaningful interpretations from the gathered data (Smith, Flowers, \& Larkin, 2009). The qualitative approach was grounded in participants' everyday contextual lived experiences and circumstances, allowing us to describe, interpret and draw telling conclusions from career changers' perceptions and experiences as student teachers. In addition, Dewey's Experiential Learning Theory (1938) with its focus on how individuals learn from past experience to grow and gain new knowledge, and Allport's definition of adult learners' 'Becoming' has informed the research study (Allport, cited in Kidd, 1973).

For Dewey, experience is the basic essence of education and educational growth. "Every experience should do something to prepare a person for later experiences of a deeper and more expansive quality. That is the very meaning of growth, continuity and reconstruction of experience" (1938, p. 47). Dewey continues, "We have the problem of ascertaining how acquaintance with the past may be translated into a potent instrumentality for dealing effectively with the future" (p. 23). We applied these principles to the learning of mature-aged students drawing on their past lives and 
experiences. We examine the continuity of experience from participants' past lives to current lives as students, and how the process shapes their 'Becoming' as they navigate change. Allport defines the 'Becoming' of an adult learner as the "process of incorporating earlier stages into later; or when this is impossible, in handling the conflict between early and later stages as well as one can" (Allport, cited in Kidd, 1973, p. 139). According to Allport, 'Becoming' is a deeply personal process and is always future oriented. Transitioning to a new career is never a smooth process; there will be tensions and frictions for the individual concerned. In this article, we argue that career-changers' prior careers and lives influence and shape their current positions as adult learners and their future roles as teachers, in ways that require them to navigate and negotiate the changes both within and beyond their being.

\section{Study design}

The study set out to identify CCSTs' characteristics and backgrounds, and to investigate their perceptions and expectations on being a student with a view to informing TE programs about ways to best support this cohort.

Survey questions comprised:

(1) Questions to garner demographic data - Participants' age; gender; educational qualifications; previous role/s, discipline area and type of teaching course enrolled in.

(2) Likert scales rating response data - Reasons for choosing teaching as a career; attributes participants believe they bring; degree of satisfaction with teaching course and practicum; concerns and support suggestions.

(3) Open-ended questions to gather qualitative data - Participants' learning needs and expectations; suggestions on personal and professional support, and ways of recognising their prior skills and experiences.

\section{Data collection}

Data collection occurred through a national online survey distributed to CCSTs enrolled in 29 Australian Universities. All 34 Australian universities offering TE programs were approached but five 
declined to convey the survey to their students, citing frequency of survey requests as their major objection. First year students were excluded as it was deemed they had insufficient experience to comment on their university learning at the early stage of the year when the survey was disseminated. The research approach and initial framing of the survey questions was informed by previous literature (Richardson \& Watt, 2006) and Varadharajan's earlier study on career change beginning teachers (2014). The study was piloted among CCSTs enrolled in a pre-service teaching program in the researchers' university. Results $(\mathrm{N}=8)$ from the pilot, including students' feedback on survey, were used to refine some items for the primary survey.

By the end of the survey period, 508 responses were received. Though responses were received from all states and territories, the majority of responses came from New South Wales, Victoria, Queensland and Tasmania (Figure 1), with fewer from South Australia, Western Australia, the Northern Territory and the Australian Capital Territory.

\section{$<$ Insert Figure 1 here $>$}

\section{Data analysis}

The study used both qualitative and quantitative modes of analysis. Qualitative responses were thematically analysed by grouping similar ideas, words and patterns (Lincoln \& Guba, 1985) to allow dominant categories to emerge that were relevant to the research study. Open-ended questions were analysed by the researchers, with at least two researchers analysing each question. Each researcher independently coded the data and then pairs conferred to achieve inter-researcher agreement on analysis by discussing variations between codes and returning to the raw data to check interpretations. Common codes were placed into appropriate themes which were shared with the other researcher(s) analysing responses to that question. 
Closed questions were analysed with the assistance of an expert statistician with summary statistics presented in the form of tables. Chi-square analysis was performed to identify significant bivariate relationships between categorical variables.

We begin with a synopsis of the major findings from the project followed by a discussion. It is noteworthy that with respect to key demographics and information on participants' backgrounds, attributes and reasons for choosing teaching, our results aligned with previous studies. However, there appeared to be limited research in earlier literature on CCSTs' learning needs, concerns and expectations as students. Our discussion and recommendations outline some of the problems and challenges associated with this cohort as well strategies that can be implemented to effectively mitigate those challenges and to maximise CCSTs' contributions to and impact on the teaching profession.

\section{Summary of key findings}

(1) CCSTs hail from diverse professions and disciplines.

(2) Their reasons for choosing teaching are primarily intrinsic and altruistic.

(3) Most respondents are satisfied with their TE program.

(4) Flexibility in course offerings and during professional experience is the most important factor valued by participants with regard to learning needs support.

(5) Acknowledgement and recognition of prior career and life experiences are deemed important by most participants.

(6) A certain paradox in participants' responses emerged (Varadharajan, Buchanan, Schuck, 2018). Many expressed a need to be treated differently while at the same time requiring the same support as any other student teacher.

\section{Key demographic data findings}

Consistent with the broader cohort of student teachers (McKenzie et al., 2014), three-quarters of those who responded were female and for the majority of the participants (well over 90\%), English 
was their first language. There were equal numbers of respondents from both regional and city universities, with a sizeable proportion (over one-third) undertaking their course on a part-time basis, indicating other commitments including work and family. The same reason could be attributed to a large proportion (44\%) choosing an online/distance study mode, concurring with previous studies (Grier \& Johnston, 2012). Table 1 outlines key demographic data related to age and educational qualifications.

\section{<Insert Table 1 here>}

As anticipated, nearly forty percent of respondents fell within two age brackets: $26-30$ years (19\%) and 41-45 years (20\%). A third of respondents was aged between 30-40 years. The rest were more dispersed. Nearly half (49\%) had graduate qualifications and another $18 \%$ had postgraduate qualifications prior to joining the TE program. The remaining $33 \%$ had high-school-leaving qualifications. These results are also consistent with previous studies indicating most CCSTs enter the TE program with graduate qualifications or beyond (Crosswell \& Beutel, 2017). Confirming previous studies (Kaldi \& Griffiths, 2013; Wilkins, 2017), graduates in this study came from various disciplines, including the STEM area, which comprised more than a quarter of the responses. Other significant qualification backgrounds included arts and business, with the rest shared among allied health services, including nursing and physiotherapy, and education-related fields.

In regard to their previous employment, the study confirmed previous research that careerchangers comprise a diverse group from various careers and disciplines (Laming \& Horne, 2013; Tigchelaar et al., 2014), as outlined in Table 2, below. Responses indicated that some participants occupied senior roles and management positions. Respondents in the education and training sector ranged from tenured academic lecturers to tutors and early childhood and school-based educators. Others had been previously employed in the mining and resources sector. The 'other' category included industries and sectors such as TAFE, Government, consulting, law, human resources, and viticulture. Each of these sectors had fewer than 10 respondents. 


\section{$<$ Insert Table 2 here $>$}

Participants were also asked which type of teacher education program or course they were enrolled in. The four most common program types with response percentages are shown below (Table 3). Other programs noted by respondents comprised undergraduate courses in secondary TE, early childhood TE and graduate diplomas in primary education. More than half of the respondents had undertaken at least one practicum or professional experience in a school.

\section{$<$ Insert Table 3 here $>$}

\section{Likert scale response findings: Teaching choice, attributes and concerns}

Items eliciting reasons why respondents chose to enter teaching were developed from existing literature (Varadharajan, 2014; Richardson \& Watt, 2005; Williams \& Forgasz, 2009). Participants were given a list of possible reasons, and for each reason, they had to provide a number from 1 to 5 , with 1 being strongly disagree and 5 being strongly agree (see Table 4 below). More than $85 \%$ chose teaching in order to make a social contribution and to share their knowledge and love for the subject area. The majority (94\%) were seeking job satisfaction. They also believed they had the necessary attributes to become a teacher. These responses suggest CCSTs' faith both in their own potential and that of the teaching profession. $29 \%$ indicated their reasons for choosing teaching derived from external factors such as stress in a previous career. In line with previous studies (e.g., Hunter-Johnston, 2015), our findings indicate that the reasons for switching careers are complex, diverse and sometimes contradictory, with a variety of push and pull factors involved in the decision-making process.

\section{$<$ Insert Table 4 here $>$}

Participants were asked to rank the top three attributes they believed they will bring to teaching. Attribute items were taken from literature studies (e.g., Richardson and Watt, 2005). Table 5 summarises these. 
$<$ Insert Table 5 here>

CCSTs believed their prior life and work knowledge and experience could be harnessed, for instance, by sharing and discussing their prior roles in the context of the subject being studied. They were keen for their knowledge and commitment to be acknowledged. The attributes correspond to the most common reasons for choosing teaching. Prior studies such as Grier and Johnston's observed that career change teachers demonstrated "authentic caring for their students and student learning that is manifested in two ways: viewing student learning as their responsibility and through making content connections in their lesson plans and teaching by using real-world examples" $(2009$, p. 71$)$. Observations such as those from prior studies resonate with the qualities of passion and commitment to teaching, as well as real-world experience that were reflected in our study.

It was hypothesised that due to career changers' ages, their experience and diverse backgrounds, many would perceive their learning needs to be different from those of other student teachers. However, only half of respondents considered their learning needs to be different, with the rest indicating they do not want to be treated differently by virtue of being a career change student.

Participants were asked to identify concerns affecting their progress as student teachers. A list of concerns, primarily informed by previous research (Richardson \& Watt, 2005, 2006), were provided and participants could tick all that were applicable. The list comprised the following items:

○ preparation for the demands of being a student teacher;

- maintaining attendance vis-a-vis the mode of study);

- completing aspects of the course requirements (e.g. academic literacy needs);

- financial implications of completing the course; balancing work, study and family;

- recognition of prior skills and experiences;

○ no concerns. 
The open-ended questions also allowed participants to outline any other matters impacting them as a CCST. The most common concerns are listed below in Table 6.

$<$ Insert Table 6 here>

Findings from open-ended questions

The open-ended questions provided more in-depth views on the lack of recognition aspect and reflected a more detailed voicing of frustration (Varadharajan, Buchanan, \& Schuck, 2018).

Respondents faced challenges trying to balance the competing demands in their lives and voiced this concern on several occasions. While it was difficult to determine from the results how many were actually in full-time employment at the time of entering the TE program, their concerns indicate several of them were working and studying concurrently. They found it hard to "juggle childcare, paid work and study" (Respondent 415). Related to this concern was the issue of cost to undertake study and professional experience. Respondents made several references to the financial sacrifice associated with returning to study. They reported existing commitments such as paying a mortgage and in the words of one, "taking massive financial hits to do this course for altruistic reasons" (R78). Recognising this difficulty, some chose to either postpone their studies until they were able to afford to do so, or opted to study part-time, despite both these options delaying their entry to the teaching profession. The quotes below reflect these sentiments.

"CCSTs are usually coming from a place of working and earning money so the change to not being able to work as much is very difficult financially" (R335)

"CCSTs have large existing financial commitments such as mortgages that are difficult to defer. Taking on part time employment is often insufficient to cover these larger existing financial commitments. I deferred entering teaching until I had sufficient savings to allow for these commitments" (R417) 
The cost aspect was particularly hard-hitting and stressful for respondents during the Professional Experience (Practicum) period as most were unable to maintain paid employment at all during that time. As one respondent observed, "It is extremely stressful trying to support a family when the nature of Practicum means I am unable to work in my usual job for 5 weeks...no work means no pay!" (R421).

\section{Need for recognition}

CCSTs clearly expressed the need to be recognised and acknowledged for their skills and experiences in the open-ended section of the survey. The literature both on career changers as well as other student teacher studies has made substantial reference to this issue (for instance, Hamilton \& O'Dwyer, 2018; McKenzie et al., 2014). The lack of recognition is cited as the second main reason (after workload) by teachers in the SiAS survey for considering leaving the profession (McKenzie et al., 2014). Given the altruistic reasons for changing to teaching and the life skills and prior experiences that the career change cohort possesses before entering the TE program, forms of recognition may be quite different for this cohort compared to school leavers. Survey participants suggested various forms in which recognition could operate. It could range from a simple acknowledgement of career changers' characteristics and their motivation to join teaching; provide opportunity to share their prior skills and experiences; recognise their prior learning; offer suitable support in light of their other life commitments and provide opportunities to hear their suggestions. Comments included:

We are experienced people that were highly regarded in our previous industry

(R189)

Acknowledging life skills, not just prior qualifications. I was a Police officer for twenty years and not one aspect of this work was recognised (R29)

Please recognise that we have done more academically challenging courses, lived in other countries, speak more than one language, and bring real world experience to teaching (R51) 


\section{Discussion}

As much as career changers have sound reasons to join the teaching profession and bring valuable qualities, there seems to be a complex interplay of external and internal factors in their long term retention. Some of the issues are paradoxical in nature and we have discussed these elsewhere (Varadharajan, Buchanan, \& Schuck, 2018). Some issues relate specifically to professional experience and this is being considered for discussion in a separate paper. We highlight here some of the complexity and uncertainty that emerged from our findings.

Career changers' own beliefs and prior assumptions about teaching and learning as they enter the TE program can be inhibitors in their adjustment to the profession and its adjustment to them. A compounding factor relates to their knowledge and prior experience. While some are experts in subject and content knowledge, deriving from their previous work and education, they do not necessarily possess the associated pedagogical knowledge (Tigchelaar et al., 2014). Others, if they have worked in education or similar fields, or are parents, may have robust 'pedagogical instincts' but they are yet to develop the theoretical backdrop to evaluate these. As a result, knowledge exchange may well differ in dealings both with (in) this cohort, and between them and school leaver entrants. Suffice it to say that each career change teacher brings to their study and work a maturity and set of experiences greater than that of their erstwhile teenaged selves.

Schools are arguably called upon to fulfil dual roles of both apprenticing young people into the workings of their society and equipping students to be critical of that same society. It stands to reason that career change teachers, with their greater beyond-school experience, can be instrumental in achieving this. As such, they potentially offer considerable threat and hope to the school system.

As mature-age students, they may have different attitudes towards their learning (for example, a deep learning approach) compared to the younger cohort (Mallman \& Lee, 2016). Failure to recognise career-changers' knowledge and experiences, and the challenges they face, can contribute to their disillusionment and consequent decision to leave the profession. 
Our study and previous studies (Laming \& Horne, 2013; Varadharajan, 2014) indicate that this cohort have not taken the decision to join teaching lightly and are typically motivated by intrinsic reasons. They are eager to form a sense of affiliation with their adopted career (Varadharajan, 2014). So, when they enter the TE program, they may already come with certain expectations, in terms of being compensated for their sacrifices and choices, as well as some weaknesses in terms of academic literacy. At the same time, they are hungry for recognition for their prior knowledge and skills and keen to pass on their experiences to future generations. This suite of factors mediates their transition through TE programs and into teaching. However, TE providers tend to design their education systems primarily with the younger school leaving cohort in mind, neglecting due consideration for those with work, family and other commitments (Hamilton \& O’Dwyer, 2018).

CCSTs' engagement with the challenges within and beyond themselves is part of their Becoming. They are navigating the multiple challenges that exist within and around them, but retain a determination to succeed in their new career. It is a process of navigating change, both within and external to themselves, but also negotiating aspirations and growth that have evolved from past experiences. Both of these can assist CCSTs in their Being and Becoming (Dewey, 1938). Life has prepared CCSTs with a breadth of experiences. Their experiences, in turn, have probably equipped them with a certain resilience, so essential to teaching. These qualities justify their place among preservice teachers, and speak to the profession's responsibility to welcome them.

We provide some recommendations for key stakeholders with a view to maximising the contribution that career changers bring to their study and work.

\section{Recommendations}

Teacher recruitment and retention are volatile, and arguably fickle. Attrition rates in the profession continue to remain high though this varies by state, subject areas and school levels (Weldon, 2018). Universities report a steady decline in the numbers enrolling for teacher preparation courses (Bahr \& Ferreira, 2018). In contrast, in some states, particularly NSW and Victoria, population growth has 
prompted the need to build more schools and hence the need for more teachers. Student population is set to increase by $26 \%$ by the year 2022 (Productivity Commission, 2012). Concurrently, there is, understandably, a push to enhance teacher quality, which is likely to constrict the intake of prospective teachers, and the retention of existing ones. Further, it is inevitable that many of those over 55 will soon retire, perhaps within the four-year typical timeframe of educating a new teacher.

One attribute that CCSTs bring to the profession is substantial beyond-school experience. Such teachers may be more likely to observe and express shortcomings in the teacher education and school systems. We not only need more teachers to teach but also teachers who have the competence and qualities to enrich and educate our students for their life-worlds (Varadharajan \& Schuck, 2017).

Education departments in Australia are looking for ways to attract and retain all teachers, including career-changers. For example, investigating incentivizing schemes such as targeted scholarships and paid internships in final school placements are under consideration in another study by the authors. TE programs are also being examined to make them more attractive to career changers, through provision, for example, of flexible study learning modes (Varadharajan, Buchanan \& Schuck, 2018). However, more can be done both at the university and school level to accommodate this growing cohort of career-change pre-service teachers. We are not claiming any easy solutions exist here in this process. However at a time when teaching appears to be becoming less attractive (Bahr \& Ferreira, 2018) and more restrictive, in a context of increasing student numbers, TE providers and school jurisdictions need to consider various options and their feasibility.

Universities and TE providers need to consider new and innovative ways in which their courses can be differentiated to suit career-changers' prior skills and knowledge in ways that maximise their learning. Differentiating the curricular offerings to account for prior knowledge may well pay dividends. At the same time, consideration must be given to career changers who have not recently undertaken studies and so may have shortfalls (such as academic or digital literacy as evidenced in this study) that are less common among the younger cohort. 
Further research could investigate alternative options for incentivizing CCSTs to teaching. Alternative entry selection modes including interviews or assessments to determine if careerchangers' prior skills are sufficient to gain entry can be examined (for instance, "A face to face interview to capture experience both career and life would be beneficial" (R19)). While it may not be apt to position career changers among the ranks of 'widening participation' schemes (Hoare \& Johnston, 2011), universities need to support career-changers who can fall under the mature age learner bracket, by ensuring they are "well supported through greater integration, recognition of and opportunities of shared prior learning experiences" which could lead to facilitating "potential mutual learning benefits for all students" (Hamilton \& O’Dwyer, 2018, p. 260).

A first step towards supporting and incentivizing TE programs and school leaders to retain this cohort is to outline CCSTs' potential contributions. CCSTs are keen for HE providers and school leaders to hear their prior stories and for both parties to have the opportunity to learn about each other in ways that benefit both. The more universities, TE providers and schools know about career-changers including about their previous careers and life experiences, the better they can effectively harness possible potentials to fulfil outcomes. A future direction for research could be to consider how previous careers can be utilised in TE programs.

All student learners navigate change as they enter university. We are proposing here that TE providers and accrediting bodies might become more familiar with and more accommodating of the strengths and limitations that all prospective teachers, including career-changers, embody. Career changers' trajectories as learners feature elements distinct from those of their school-leaver counterparts. This presents both a challenge and an opportunity. Evidence-based enhancement of their professional growth is a crucial part of assisting their 'Becoming' into the profession.

\section{References}


Anthony, G., \& Ord, K. (2008). Change-of-career secondary teachers: Motivations, expectations and intentions. Asia-Pacific Journal of Teacher Education, 36(4), 359-376.

Bahr, N. \& Ferreira, J-A. (2018). Seven reasons people no longer want to be teachers. The Conversation, April 16 2018. Retrieved from https://theconversation.com/seven-reasons-people-no-longerwant-to-be-teachers-94580

Burton, K., Golding Lloyd, M., \& Griffiths, C. (2011). Barriers to learning for mature students studying HE in an FE college. Journal of Further and Higher Education, 35(1), 25-36.

Crosswell, L., \& Beutel, D. (2017). $21^{\text {st }}$ century teachers: How non-traditional pre-service teachers navigate their initial experiences of contemporary classrooms. Asia-Pacific Journal of Teacher Education, 45(4), 416-431.

Cuddapah, J.L., \& Stanford, B.H. (2015). Career changers' ideal teacher images and grounded classroom perspectives. Teaching and Teacher Education, 51, 27-37.

Dewey, J. (1938). Experience and education. London: Collier Macmillan Publishers.

Grier, J. M., \& Johnston, C. C. (2009). An inquiry into the development of teacher identities in STEM career changers. Journal of Science Teacher Education, 20, 57-75.

Grier, J.M., \& Johnston, C.C. (2012). STEM professionals entering teaching: Navigating multiple identities. Journal of Science Teacher Education, 23(1), 19-44.

Hamilton, M., \& O’Dwyer, A. (2018). Exploring students learning approaches in an initial teacher education programme: A comparison of mature learners and direct entry third-level students. Teaching and Teacher Education, 71, 251-261.

Hart Research Associates (2010). Career changers in the classroom: A national portrait. Washington: Peter. D. Hart Research Associates, Inc. Retrieved from http://woodrow.org/wp/wpcontent/ uploads/2013/06/CareerChangersClassroom_0210.pdf

Hoare, A., \& Johnston, R. (2011) Widening participation through admissions policy - a British case study of school and university performance. Studies in Higher Education, 36(1), 21-41. 
Hunter-Johnson, Y. (2015). Demystifying the Mystery of Second Career Teachers' Motivation to Teach. The Qualitative Report, 20(8), 1359-1370.

Kaldi, S., \& Griffiths, V. (2013). Mature students experiences in teacher education: widening participation in Greece and England. Journal of Further and Higher Education, 37(4), 552-573.

Kee, A.Y. (2012). Feelings of preparedness among alternatively certified teachers: what is the role of program features? Journal of Teacher Education, 63(1), 23-28.

Kidd, J.R. (1973). How Adults Learn. New York: Association Press.

Laming, M.M., \& Horne, M. (2013). Career change teachers: a pragmatic choice or a vocation postponed. Teachers and Teaching: theory \& practice, 19(3), 326-343.

Lincoln, Y.S., \& Guba, E.G. (1985). Naturalistic inquiry. Beverly Hills, California: Sage Publications.

McKenzie, P., Rowley, G., Weldon, P., \& Murphy, M. (2014). Staff in Australia's Schools 2013: Main report on the survey. Melbourne, Australia: Australian Council for Educational Research.

Mallman, M., \& Lee, H. (2016). Stigmatised learners: mature age students negotiating university culture. British Journal of Sociology of Education, 37(5), 684-701.

Priyadharshini, E., \& Robinson-Pant, A. (2003). The attractions of teaching: An investigation into why people change careers to teach. Journal of Education for Teaching: International Research and Pedagogy, 29 (2), 95-112.

Productivity Commission (2012), Schools Workforce, Research Report, Canberra, Retrieved http://www.pc.gov.au/inquiries/completed/education-workforce-schools/report/schoolsworkforce.pdf

Richardson, P. W., \& Watt, H. M. G. (2005). 'I've decided to become a teacher': Influences on career change. Teaching and Teacher Education, 21 (5), $475-489$.

Richardson, P. W., \& Watt, H. M. G. (2006). Who chooses teaching and why? Profiling characteristics and motivations across three Australian universities. Asia Pacific Journal of Teacher Education, 34 (1), 27-56. 
Smith, J.A., Flowers, P., \& Larkin, M. (2009). Interpretive phenomenological analysis: Theory, method and research. London: Sage Publications.

Tigchelaar, A., Vermunt, J.D., \& Brouwer, N. (2014). Patterns of development in second-career conceptions of teaching and learning. Teaching and Teacher Education, 41, 111-120.

Varadharajan, M. (2014). Understanding the lived experiences of second career beginning teachers.

(Doctoral dissertation). Sydney: University of Technology Sydney.

http://hdl.handle.net/10453/29255

Varadharajan, M., \& Schuck, S. (2017). Can Career Changers be Game Changers? Policy, Research and Practice Concerning Career Changers. In J. Nuttall, A. Kostogriz, M. Jones, M \& J. Martin, (Eds.), Teacher Education Policy and Practice: Evidence of Impact, Impact of Evidence (pp. 8395). Singapore: Springer.

Varadharajan, M., Buchanan, J. \& Schuck, S. R. (2018). Changing course: the paradox of the career change student-teacher, Professional Development in Education, 44 (5), 738-749.

Watters, J.J., \& Diezmann, C.M. (2015). Challenges confronting career change beginning teachers: A qualitative study of professional scientists becoming science teachers. Journal of Science Teacher Education, 26, 163-192.

Weldon, P. R. (2018). Early career teacher attrition in Australia: evidence, definition, classification and measurement. Australian Journal of Education, Australian Council of Educational Research, 62(1), 61-78.

Wilkins, C. (2017). 'Elite' career-changers and their experience of initial teacher education. Journal of Education for Teaching, 43(2), 170-190.

Williams, J.J., \& Forgasz, H. (2009). The motivations of career change students in teacher education. Asia-Pacific Journal of Teacher Education, 37(1), 95-108. 
Navigating and negotiating: Career changers in Teacher Education programs

Figure 1: Survey response by State

States/Territories Responses

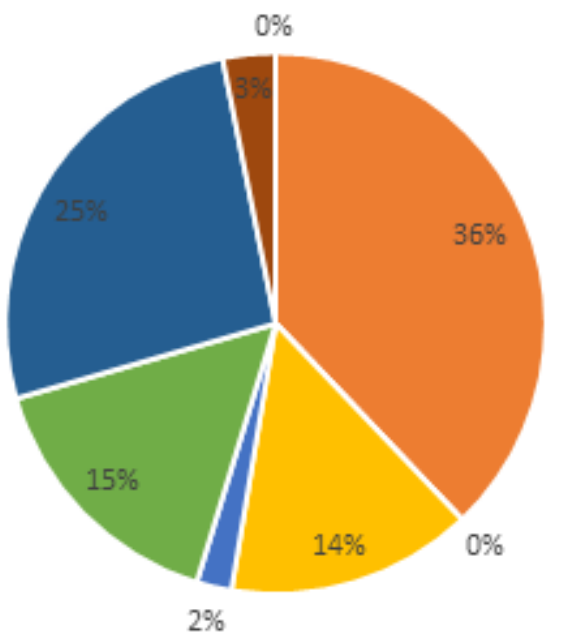

- ACT " NSW $\|$ NT $\|$ Queensland "SA | Tasmania "Victoria "WA 
Navigating and negotiating: Career changers in Teacher Education programs

Table 1: Age and educational qualifications

\begin{tabular}{|c|c|c|c|}
\hline Age & Percentage (\%) & $\begin{array}{l}\text { Educational } \\
\text { Qualifications }\end{array}$ & Percentage (\%) \\
\hline $21-25$ & $13 \%$ & \multirow[b]{2}{*}{ Graduate } & \multirow[t]{2}{*}{$49 \%$} \\
\hline $26-30$ & $19 \%$ & & \\
\hline & & \multirow{3}{*}{ Post-Graduate } & \multirow[t]{3}{*}{$18 \%$} \\
\hline $31-35$ & $16 \%$ & & \\
\hline & $17 \%$ & & \\
\hline $36-40$ & & \multirow{3}{*}{ School-leaver } & \multirow[t]{3}{*}{$33 \%$} \\
\hline $41-45$ & $20 \%$ & & \\
\hline eer 45 years & $15 \%$ & & \\
\hline
\end{tabular}

Table 2: Field of employment

\begin{tabular}{|c|c|c|c|c|c|c|c|c|c|}
\hline Field: & $\begin{array}{l}\text { Health } \\
\text { Sector }\end{array}$ & $\begin{array}{l}\text { Hospitality } \\
\text { Tourism } \\
\text { Sector }\end{array}$ & $\begin{array}{l}\text { Education } \\
\text { Sector }\end{array}$ & $\begin{array}{l}\text { Management/ } \\
\text { Banking/ } \\
\text { Finance } \\
\text { Sector }\end{array}$ & $\begin{array}{l}\text { Media/ } \\
\text { Advertising/ } \\
\text { Arts } \\
\text { Sector }\end{array}$ & $\begin{array}{l}\text { Construction } \\
\text { Mining } \\
\text { Sector }\end{array}$ & $\begin{array}{l}\text { Retail } \\
\text { Sector }\end{array}$ & Other & $\begin{array}{c}\text { No } \\
\text { response }\end{array}$ \\
\hline $\mathrm{N}=508$ & 50 & 50 & 34 & 33 & 35 & 32 & 34 & 160 & 40 \\
\hline
\end{tabular}

Table 3: Most prevalent TE programs

\begin{tabular}{|c|c|c|}
\hline Type of program & Numbers & \% \\
\hline Undergraduate Primary & 114 & 24 \\
\hline Master of Teaching (Primary) & 98 & 19 \\
\hline $\begin{array}{c}\text { Master of Teaching } \\
\text { (Secondary) }\end{array}$ & 90 & \\
\hline
\end{tabular}


Table 4: Reasons to enter teaching

\begin{tabular}{|c|c|}
\hline Reasons for choosing teaching & $\begin{array}{c}\% \\
\text { (agree/strongly } \\
\text { agree) }\end{array}$ \\
\hline I believe I have the necessary attributes to be a teacher & 94 \\
\hline I want a career that gives me job satisfaction & 94 \\
\hline $\begin{array}{l}\text { I want to share my knowledge and love for the content/subject } \\
\text { area }\end{array}$ & 87 \\
\hline I want to make a social contribution & 87 \\
\hline I want a stable and secure career & 81 \\
\hline I want to share my prior career and life experiences & 78 \\
\hline Teaching offers balance between work and family & 70 \\
\hline Attracted by TE program options and pathways & 44 \\
\hline Due to stress in previous career & 29 \\
\hline
\end{tabular}

Table 5: Attributes

\begin{tabular}{|l|l|c|}
\hline \multicolumn{1}{|c|}{ Commonly cited attributes } & $\%$ \\
\hline 1 & Passion and enthusiasm & $33 \%$ \\
\hline 2 & Life/Real world experience & $27 \%$ \\
\hline 3 & Commitment to teaching & $14 \%$ \\
\hline 4 & Maturity and wisdom & $10 \%$ \\
\hline 5 & Content knowledge & $<10 \%$ \\
\hline 6 & Career experience & $<10 \%$ \\
\hline
\end{tabular}

Table 6: Concerns

\begin{tabular}{|l|l|c|}
\hline & \multicolumn{1}{|c|}{ Commonly cited concerns } & $\%$ \\
\hline 1 & Balancing study with work and life commitments & $27 \%$ \\
\hline 2 & Financial burden of being a student again & $20 \%$ \\
\hline 3 & Academic literacy needs & $14 \%$ \\
\hline 4 & Felt under-prepared for course demands & $10 \%$ \\
\hline 5 & Lack of recognition of prior skills and experiences & $10 \%$ \\
\hline
\end{tabular}

